\title{
Low Probability Activation of Bax/Bak Can Induce Selective Killing of Cancer Cells by Generating Heterogeneity in Apoptosis
}

\author{
Subhadip Raychaudhuri ${ }^{1 *}$ and Somkanya C Das ${ }^{2,3}$ \\ ${ }^{1}$ Department of Chemistry, ${ }^{2}$ Genome Center, ${ }^{3}$ Department of Biomedical Engineering \\ University of California, Davis, California, USA
}

Submitted July 2012. Accepted for publication November 2012.

\begin{abstract}
Biomimetic pro-apoptotic agents (e.g., $\mathrm{BH} 3$ mimetics) have been shown to activate the intrinsic death pathway (Type 2 apoptosis) selectively in cancer cells, a mechanism that can be key to developing successful anti-cancer therapy. This work reports mathematical modeling and computer simulations to explore the mechanisms for cancer cell apoptosis. The results indicate that a combination of low probability Bid-Bax type reaction along with overexpressed reactant molecules allows specific killing of cancer cells. Low-probability activation of Bax also emerges as a basis for inherent cell-to-cell variability in apoptotic activation. Variations in Bcl-2 to Bax ratio within a cancer cell population can further affect intrinsic fluctuations generated due to the stochastic Bid-Bax reaction. Such heterogeneity in apoptosis resistance can also provide a mechanism for the origin of cells with higher tumorigenic potential (cancer stem-like cells). The implications of our results for cancer therapy, such as in minimizing stochastic fluctuations in cancer cell death, are discussed.
\end{abstract}

Keywords: BH3 only proteins, Bcl-2, stochastic differential equations, Monte Carlo, single cell analysis

\section{INTRODUCTION}

Finding the mechanisms for inducing selective apoptotic death of cancer cells, while leaving normal cells intact, remains a key issue in cancer biology. BH3 mimetic molecules such as HA14-1 or ABT-737 have been shown to selectively kill cancer cells by activating the intrinsic signaling pathway of apoptosis, while leaving normal cells unharmed [1-12]. There is an intense interest recently in the mechanism of $\mathrm{BH} 3$ only proteins as $\mathrm{BH} 3$ mimetics are emerging as an apoptosis rescuer for certain types of resistant cancer cells,

*Corresponding author: Subhadip Raychaudhuri, Department of Chemistry, University of California, Davis, California 95616, USA. Phone: 530574 6868. E-mail: raychaudhuri@ucdavis.edu, subraychaudhuri@gmail.com. Other author: scdas@ucdavis.edu. 
and several plausible models for activation have been proposed [1-28]. Can increased apoptotic vulnerability (to $\mathrm{BH} 3$ mimetics) of cancer cells be explained by high expression levels of $\mathrm{BH} 3$ only activators (such as Bid) [13-14] and/or Bax-like (multidomain proapoptotic) molecules in cancer cells together with a low probability Bid-Bax type reaction event? It has been shown that hydrocarbon-stapled $\mathrm{BH} 3$ peptides (Bid$\mathrm{SAHB}_{\mathrm{A}} / \mathrm{Bim} \mathrm{SAHB}_{\mathrm{A}}$ ) enable direct reaction with Bax leading to the release of cytochrome c [15-16]. Increased expression of apoptotic inhibitors, such as Bcl-2 proteins, however, would prevent the Bid-Bax type reaction and protect cancer cells from apoptotic death [13, 29-31]. In addition, a fraction of cancer cells, such as the CD34+CD38- phenotype of leukemic stem cells [32], can become particularly resistant to apoptotic stress partly due to pronounced overexpression of antiapoptotic proteins such as Bcl-2.

In previous studies, mathematical and computational approaches have been taken to clarify the basis of cell-to-cell stochastic variability in Type 2 (mitochondrial) apoptotic activation [33-34]. Part of this cell-to-cell variability originates from inherent stochasticity of signaling reactions during apoptotic activation [11-12, 33-35]. Cell-tocell variability in apoptosis can also arise from cellular variability in concentrations of key apoptotic regulators such as Bcl-2 [11-12,36]. Both types of cell-to-cell variability (with slow activation), in Type 2 apoptosis, can also be considered as variability in apoptosis resistance. Whether such heterogeneity in apoptosis resistance can be linked to variability in the tumorigenic/leukemogenic potential of cancer cells needs to be explored but seems probable based on recent studies in immunocompromised mice [37-40]. The hypothesis of cancer stem cells (CSC) or cancer stem-like cells (CSLCs) has its origin in the variability in the tumorigenic/leukemogenic potential among cancer cells [37-40]. Inherent stochastic activation (in Type 2 apoptosis) would support the possibility that all cancer cells have similar but low proliferation potential in in vitro colony forming assay or in vivo transplantation assay [37]. In contrast, apoptotic heterogeneity arising due to cellular variability in signaling proteins might be of epigenetic origin, and supports a model where only a small subset of cancer cells possesses increased apoptosis resistance and extensive proliferation potential [32, 37-40]. Computational study of the intrinsic pathway of apoptosis enables to estimate the contributions from both inherent stochastic fluctuations and cellular variations in protein levels in generating cell-to-cell variability in apoptosis resistance of cancer cells.

In this work, the intrinsic pathway of apoptosis is studied, in which activation is initiated through the regulatory loop created by Bid-Bax-Bcl-2. A stochastic differential equation-based model elucidates the inherently stochastic nature of a low probability Bid-Bax reaction. A detailed kinetic Monte Carlo model is then applied to simulate both pre- and post-mitochondrial signaling modules in the intrinsic apoptotic pathway. Even though a low probability Bid-Bax reaction and its Bcl-2 inhibition can be postulated, lack of measurements of Bid-Bax reaction constants and cell-type-specific $\mathrm{Bid} / \mathrm{Bax} / \mathrm{Bcl}-2$ protein levels makes any quantitative study of apoptotic activation in cancer cells difficult. Computational approach is taken to estimate an approximate value for the low probability Bid-Bax reaction constant that is further used in subsequent simulations. We demonstrate how a low probability Bid-Bax reaction (or a similar one that activates Bax and/or Bak) can protect normal cells from apoptotic activation and selectively kill cancer cells having overexpressed $\mathrm{BH} 3$ only activator 
proteins. Thus, when the apoptotic inhibition of Bcl-2 proteins is overwhelmed by $\mathrm{BH} 3$ (sensitizer) mimetic molecules, cancer cells become more vulnerable to apoptotic death than normal cells [1-25]. This low probability Bid-Bax reaction also provides a novel mechanism for the cell-to-cell stochastic variability inherent in apoptotic activation. Increasing the Bcl-2 to Bax ratio is shown to amplify the inherent stochastic fluctuations arising from Bid-Bax reaction and thus provides a mechanism for generation of cells with higher tumorigenic potential (CSLCs). We further discuss possible strategies to eliminate large cell-to-cell stochastic fluctuations in the intrinsic apoptotic pathway of cancer cells.

\section{METHODS}

This section briefly discusses the signaling model under study and then describes the two computational approaches, stochastic differential equations and Monte Carlo simulations, taken in this study.

\subsection{The Signaling Model for Bid-Bax Reaction Mediated Apoptotic Activation} In this work, a simplified network model was developed and studied for apoptotic signaling triggered by the direct Bid-Bax reaction (Figure 1) [41]. In our previous

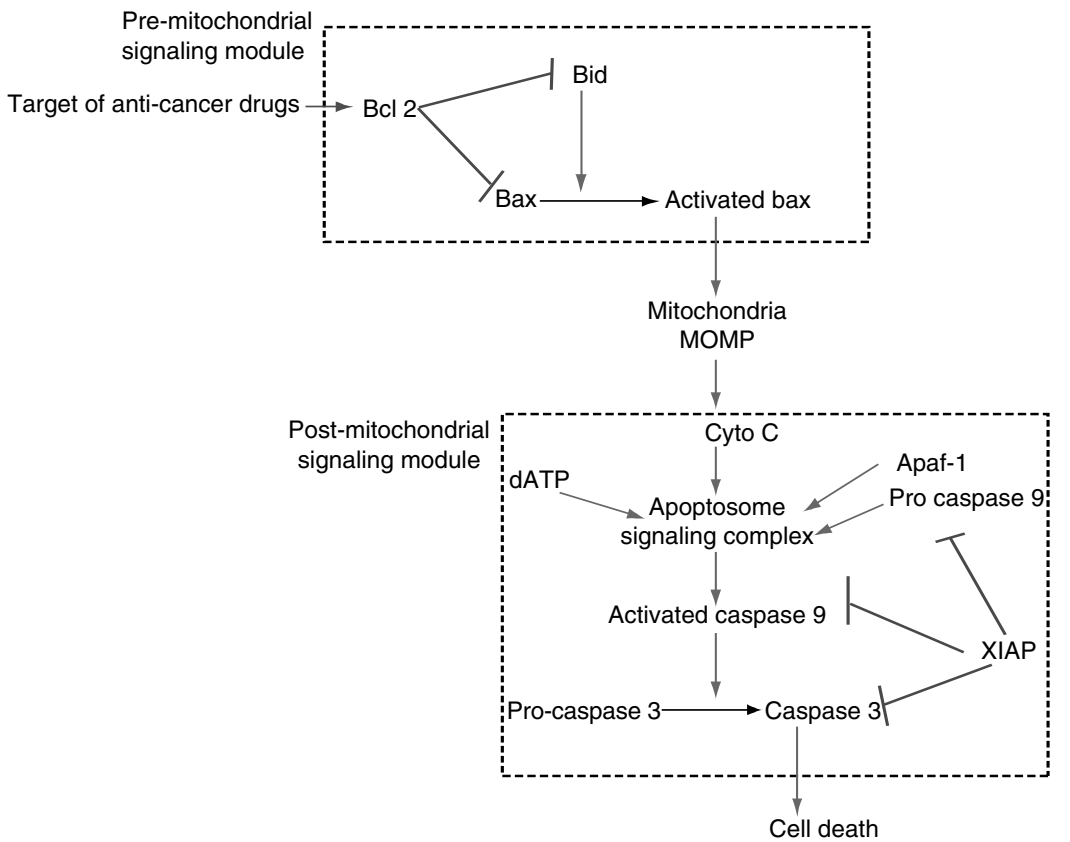

Figure 1. Schematic of a simplified signaling network for the intrinsic (mitochondrial) pathway of apoptosis. Bid-Bax reaction activates the premitochondrial signaling module resulting in release of mitochondrial cytochrome $\mathrm{c}$ and activation of effector caspases (captured by caspase 3 in our model) in the post-mitochondrial signaling module. 
computational studies, Bid-tBid conversion reaction was considered to activate the intrinsic pathway of apoptosis [11-12, 33, 35]. Activation of Bax by tBid, in the premitochondrial signaling module (Figure 1), has been extensively studied in the context of apoptosis and necroptosis [33, 41-46]. The current study, however, considers that Bcl-2 inhibition by itself can lead to the activation of the pre-mitochondrial signaling module through a direct Bid-Bax type reaction. Cytochrome $\mathrm{c}$ is released into the cytosol in an all-or-none manner when Bax activation reaches a pre-assigned threshold value [47]. In our model, Bcl-2 (B cell lymphoma protein 2) represents all the Bcl-2 family proteins (such as Bcl-2, Bcl-xL, Mcl-1) with similar anti-apoptotic properties [30-31]. In a similar manner, Bid is representative of $\mathrm{BH} 3$ only activators that can directly react with Bax-like multidomain proapoptotic molecules such as Bax and Bak (captured by Bax in our model) [30-31]. We do not explicitly simulate BH3 only sensitizers (such as Bad or Bik) [1, 30-31], whose effect can be simulated by varying $\mathrm{Bcl}-2$ concentrations. Presence of multiple functionally similar proteins and their varied expression levels (depending on cell type) make the apoptotic pathway more complex than the present model can address. However, coarse-graining the pathway by representative proteins allows us to capture some of the essential biology of systemlevel apoptotic regulation.

\subsection{Stochastic Differential Equations (SDEs)}

Signaling reactions that describe binding-unbinding between the i-th pair of molecular reactants $\left(A^{i}+B^{i} \rightleftarrows C^{i}\right)$ are modeled by the following set of stochastic differential equations:

$$
d A^{i}=d B^{i}=-d C^{i}=-k_{o n}^{i} A^{i} B^{i} d t-\sqrt{k_{o n}^{i} A^{i} B^{i}} d W+k_{o f f}^{i} C^{i} d t+\sqrt{k_{o f f}^{i} C^{i}} d W
$$

where $k_{\text {on }}\left(k_{\text {off }}\right)$ denotes the forward (backward) kinetic reaction rate constant; $W$ is a Weiner process [48-49], and $t$ is time. Stochastic equations were derived from the corresponding master equations that describe the signaling reaction of a given type [48]. In addition to the binding-unbinding type reactions, Bax can be converted to an activated form when dissociated from the Bid-Bax complex. Such catalytic activation reaction is included in the model using a term similar to the dissociation reaction and a similar rate constant. Stochastic equations can lead to analytical estimates of pertinent physical quantities, such as the amount of Bcl-2 proteins needed to completely block the direct Bid-Bax reaction. In addition, stochastic differential equations can be utilized to determine the phase diagram for a stochastic-to-deterministic transition in the relevant parameter space [34]. Thus, such stochastic equations are well suited to elucidate the basis of inherent stochastic fluctuations in signaling reactions.

The SDE that captures low probability Bid-Bax association was solved using a Poisson Runge-Kutta scheme [50]. In this method, the number of times a specific reaction channel fires in a given time $t$ is a Poisson random variable with mean $\lambda t$ and variance $\lambda t$, where $\lambda$ is the propensity function. For the Bid-Bax association reaction $\lambda=k_{\text {on }}[\mathrm{Bid}][\mathrm{Bax}]$ where [] denotes the concentration of a molecular species. All other 
reaction SDEs were solved using the standard Euler-Maruyama numerical scheme for solving stochastic differential equations [50-51]. The system is partitioned into subsets of slow and fast reactions in a manner such that the slow Bid-Bax binding reaction is considered with a stepsize of $\tau$ within which all other (fast) reactions are repeatedly solved [50].

\subsection{Kinetic Monte Carlo Simulations}

A detailed computational study is carried out utilizing kinetic Monte Carlo (MC) simulations of pre- and post-mitochondrial signaling events [33]. Kinetic reaction rates (such as $k_{o n} / k_{o f f}$ ) and molecular concentrations are obtained from values reported in the literature $[46,52-55]$ and provided in the appendix. Each MC step is chosen to be $10^{-4} \mathrm{~s}$; a typical simulation involved $10^{8}-5 \times 10^{8} \mathrm{MC}$ steps. MC approach is well suited to simulate some of the complexities of signaling reactions such as the spatial heterogeneity involved in signaling reactions. Bax molecules, for example, translocate to mitochondria upon activation. In the MC model, Bax activation is modeled in a more complex manner than in the SDE model and mediated by formation of Bax homodimers [33]. Cytochrome c release (once the number of activated Bax dimers reached a threshold) leads to cytochorme $\mathrm{c}-$ Apaf binding and the subsequent formation of multimolecular cyto c-Apaf-ATP complex apoptosome. Formation of the apoptosome complex is modeled in a simplified manner where Apaf represents the Apaf-ATP complex. In MC simulations, cytochrome $\mathrm{c}$ and Apaf molecules need to have spatial proximity before a binding reaction can occur between them, and such diffusion limitation introduces additional probability into the cytochrome c-Apaf binding reaction. Low probability of apoptosome formation generates stochastic variability in apoptotic activation, but once formed, induces rapid activation of downstream caspases 9 and $3[33,56]$. Activation of caspase 3 can be taken to be a downstream readout of apoptotic cell death signaling; MC simulations are carried out to measure the timecourse of caspase 3 activation at a single cell level.

\subsection{Estimation of Bid-Bax and Bid-Bcl-2 Reaction Constants}

Given the lack of the knowledge of Bid-Bax reaction constants, MC simulations are performed to estimate a low probability of reaction (affinity $k_{A}=k_{\text {on }} / k_{\text {off }} \sim 10^{5} \mathrm{M}^{-1}$ ) that can activate the Type 2 pathway only when Bid and Bax are significantly ( 5-fold) overexpressed, as possibly found in cancer cells, but would prevent similar activation in normal cells. Bid-Bcl-2 reaction constant is also assumed to be low $\left(K_{A} \sim 10^{6} \mathrm{M}^{-1}\right)$, consistent with the low activation constant of direct Bid-Bax reaction. It has been noted that truncated Bid (tBid) has approximately 10-fold higher affinity toward Bcl-xL fusion protein compared to full-length Bid [57]. Bid-Bax-Bcl-2 creates a regulatory loop network in the pathway and we have studied the effect of variation in concentrations of all three molecules that define the loop. Variations in Bcl-2 can capture the effect of posttranslational cellular variability in such anti-apoptotic protein levels as well as the action of targeted inhibitors such as BH3 (sensitizer) mimetic agents. Even though our previous computational study has explored the effect of Bcl-2 on cell-to-cell variability in apoptotic activation (triggered by activated caspase8) [11-12, 33], the impact of 
$\mathrm{Bcl}-2$ inhibition is different when the intrinsic pathway is activated by the direct Bid-Bax reaction. We use a stochastic-differential-equation-based model of the pre-mitochondrial signaling module to elucidate the mechanisms of stochastic fluctuations resulting from low probability Bid-Bax type reactions.

\section{RESULTS}

\subsection{Stochastic Differential Equations: Cell-to-Cell Variability Arises from Bid-Bax Reaction}

All three molecules in the Bid-Bax-Bcl-2 regulatory loop (Figure 1) undergo pairwise binding-unbinding reactions and each of which can be described by SDEs in the form of eqn. 1. The SDEs were solved using a hybrid method that combines two different numerical solution techniques described in Section 2. Molecular numbers are estimated for a $1 \mu \mathrm{m}^{3}$ simulation volume from known molar concentrations [46, 52-55] and discussed in detail in our previous works [11-12, 33, 35]. Bax was not activated when we used regular concentrations (as found in normal cells): $\mathrm{Bid}=20, \mathrm{Bax}=50, \mathrm{Bcl}-2=45$ (molecules). A 2-fold overexpression in Bid and Bax, however, was sufficient to activate Bax, and hence the pre-mitochondrial signaling module, in a stochastic manner (time-to-cyto c release averaged over 100 cells: $1368 \mathrm{sec}$ ). Thus, even when all the cellular parameters remain identical in a cell population, inherent stochastic fluctuations in the Bid-Bax reaction generates large cell-to-cell variability in cytochrome c release. Kinetic reaction rate constants for the low probability Bid-Bax reaction determine the overexpression levels in Bid (and/or Bax) molecules needed for activation as well as the extent of cell-to-cell stochastic variability in Bax activation. In the cellular environment, diffusion limitation will lead to an effective lower rate of Bid-Bax reaction requiring increased overexpression of Bid and Bax molecules (for Bax activation). This aspect will be further clarified in our MC studies. A 10-fold overexpression of Bid only (or Bax only) was also sufficient to activate Bax; the average (over 100 cells) time needed to release cytochrome $\mathrm{c}$ was higher for Bid overexpression $(1045 \mathrm{sec})$ than that for Bax overexpression $(397 \mathrm{sec})$. When Bid and Bax are both 10-fold overexpressed, rapid activation of Bax resulted in further decrease in the average time-to-cyto c release. Cytochrome $\mathrm{c}$ release, as a result of threshold Bax activation, took longer as a larger number of Bcl-2 is used, as shown in Figure 2 with Bcl-2 =45, 450, and 675 (Bid = 200 , Bax $=500)$. The average time-to-cyto c release, for all three Bcl-2 values, is also shown in Figure 2. As the Bcl-2 to Bax ratio exceeds 1 in our model (Figure 2c), the time-to-cyto c release significantly increases. Diffusion in the cellular environment, which is not captured by the present SDE model, will have significant additional impact on the time-scale of activation.

Cell-to-cell stochastic variability in time-to-cyto c release, which arises due to low probability of Bid-Bax association reaction and subsequent rapid release of cytochrome c [47], also increases with Bcl-2 levels and remains very sensitive to the Bcl-2 to Bax ratio (standard deviation $\delta$ measured over 100 single cell runs: $\delta=11 \mathrm{sec}$ for Bcl-2 $=45$, $\delta=63 \mathrm{sec}$ for $\mathrm{Bcl}-2=450, \delta=338 \mathrm{sec}$ for $\mathrm{Bcl}-2=675$ ). This remarkable sensitivity to Bcl-2 to Bax ratio results from strong Bax-Bcl-2 binding (affinity $k_{A}=k_{\text {on }} / k_{\text {off }} \sim 10^{8} \mathrm{M}^{-1}$ ) 

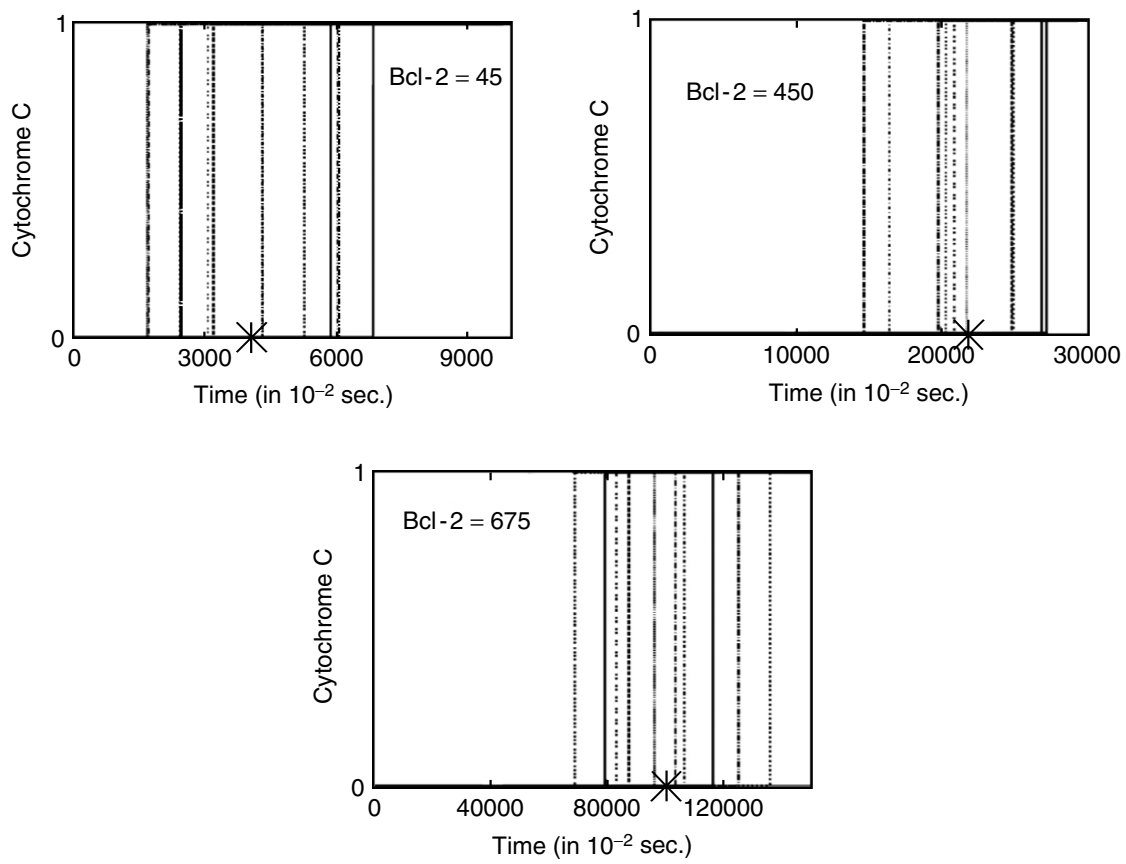

Figure 2. Cytochrome c release (as a result of threshold Bax activation in the SDE model) is shown for single cells with three numbers of Bcl-2 molecules: 45, 450, and $675(\mathrm{Bid}=200, \mathrm{Bax}=500)$. Rapid all-or-none type release of cytochrome $\mathrm{c}$ is approximated by a sharp spike (step function) and normalized (relative to its maximum value) data are shown. SDEs were solved with a time-step $\Delta t=10^{-2} \mathrm{sec}$; time is shown in multiples of the time-step $\Delta t$. Data are shown for 10 single cell runs (each vertical line corresponds to a single cell). The average time-to-cyto c release: $4.1 \times$ $10^{3} \mathrm{MC}$ steps for Bcl-2 = 45, $2.2 \times 10^{4} \mathrm{MC}$ steps for Bcl-2 $=450,1 \times 10^{5}$ MC steps for Bcl-2 $=675$ (marked by $*$ ). Note that the time-scale of cytochrome $\mathrm{c}$ release significantly changes as the $\mathrm{Bcl}-2$ to Bax ratio exceeds one $(\mathrm{Bcl}-2=675)$.

and simultaneous weak binding between Bid and $\mathrm{Bax} / \mathrm{Bcl}-2\left(k_{A} \sim 10^{6} \mathrm{M}^{-1}\right.$ or less). Very high Bcl-2 levels led to strong inhibition of low probability Bid-Bax reaction and thus provide a mechanism for apoptosis resistance of cancer cells. Given the time-scale to solve the signaling reactions, Bcl-2 to Bax ratio $\sim 5$ completely blocked Bax activation and cytochrome c release (over a wide range of Bid and Bax overexpressions). Similar Bcl-2 to Bax ratio (to inhibit Bax activation) was estimated by analyzing the rate equations for Bid-Bax and Bcl-2-Bax reactions. Thus, variation in Bcl-2 expression can be a mechanism through which cancer cells create heterogeneity in apoptotic resistance within a tumor. 


\subsection{Stochastic to Deterministic Transition in Cancer Cell Death}

A 10-fold overexpression of Bid and Bax while keeping the Bcl-2 level normal significantly diminished cell-to-cell stochastic variability. Such a result can be seen from comparing the deterministic and stochastic terms in the SDE for Bid-Bax reaction. We also compared the Bcl-2-Bax binding/unbinding reaction terms and estimated the ratio of Bax to Bcl-2 ( $\sim 6)$ to be sufficient for overcoming the Bcl-2 inhibition of BidBax reaction. Therefore, when Bax to Bcl-2 ratio exceeds a threshold value, as well as the product of $\mathrm{Bid}$ and $\mathrm{Bax}$ concentrations is higher than $1 /\left(k_{o n}\right)^{1 / 2}$ for the Bid-Bax association reaction, one expects a stochastic-to-deterministic transition in Bax activation and in the release of mitochondrial cytochrome c. Such a stochastic-todeterministic transition will be unique to apoptotic activation in cancer cells, and thus it can play a crucial role in developing a successful strategy for killing cancer cells by targeting the intrinsic pathway. Otherwise, inherent stochastic variability in the activation of pre-mitochondrial signaling module is a characteristic feature of cancer cell death, and partly explains the variability in apoptotic vulnerability among cancer cells. Such inherent variability can be highly relevant to apoptosis resistance within a genetically distinct sub-clonal tumor population [58-59].

\subsection{Kinetic Monte Carlo Simulation: Stochastic Bax Activation through Low Probability Bid-Bax Reaction}

In our kinetic MC simulations, a set of signaling molecules that belong to the pre- and post-mitochondrial signaling modules (Figure 1) are initially distributed randomly and uniformly [33]. Signaling molecules are then randomly sampled for diffusion and reaction moves with predefined probability constants as described in Section 2. Probabilistic parameters used in our simulations are estimated from known values of kinetic and diffusion rate constants $[33,46,52-55]$ and provided in the appendix. Estimation of molecular numbers $\left[\sim 0.6 \times\right.$ nano-molar concentration $\left.\left(1 / \mu \mathrm{m}^{3}\right) \times V\left(\mu \mathrm{m}^{3}\right)\right]$ for the simulation volume has been discussed in our previous work [11-12, 33, 35]. For Bid (33.3 nM), Bax (83.3 nM), Bcl-2 (75 nM) levels found in normal cells, a Bid-Bax association constant of $10^{3} \mathrm{M}^{-1} \mathrm{~s}^{-1}\left(<k_{\text {on }}\right.$ for tBid-Bax: $\left.2 \times 10^{5} \mathrm{M}^{-1} \mathrm{~s}^{-1}\right)$, and a dissociation constant of $0.01 \mathrm{~s}^{-1}$ ( $k_{\text {off }}=0.02 \mathrm{~s}^{-1}$ for tBid-Bax), protect normal cells from apoptosis. A 2-fold increase in Bid and Bax level still did not activate Bax. The effect of low rate constant Bid-Bax reaction on Bax activation is stronger in the MC model than in the SDE model; such effect can be attributed to the additional requirement of spatial encounter of reactant molecules, by diffusive transport, in the MC model. Increasing the level of Bid and Bax by 10-fold while keeping the Bcl-2 concentration normal led to significant Bax activation and cytochorme $\mathrm{c}$ release (Figure 3, top panel). The association constant $k_{\text {on }}=10^{3} \mathrm{M}^{-1} \mathrm{~s}^{-1}$ was used for all further simulations; slight variations in this value would not change the qualitative results presented here.

\subsection{Bcl-2 to Bax Ratio Modulates Stochastic Variability Generated due to Bid-Bax Reaction}

Bcl-2 over-expression has been observed in a variety of cancer cells and is a marker for poor prognosis [13, 29]. In CD34+ AML (acute myeloid leukemia) cells, possibly a stem cell phenotype, Bcl-2 has been shown to be highly over-expressed [60-61]. In 

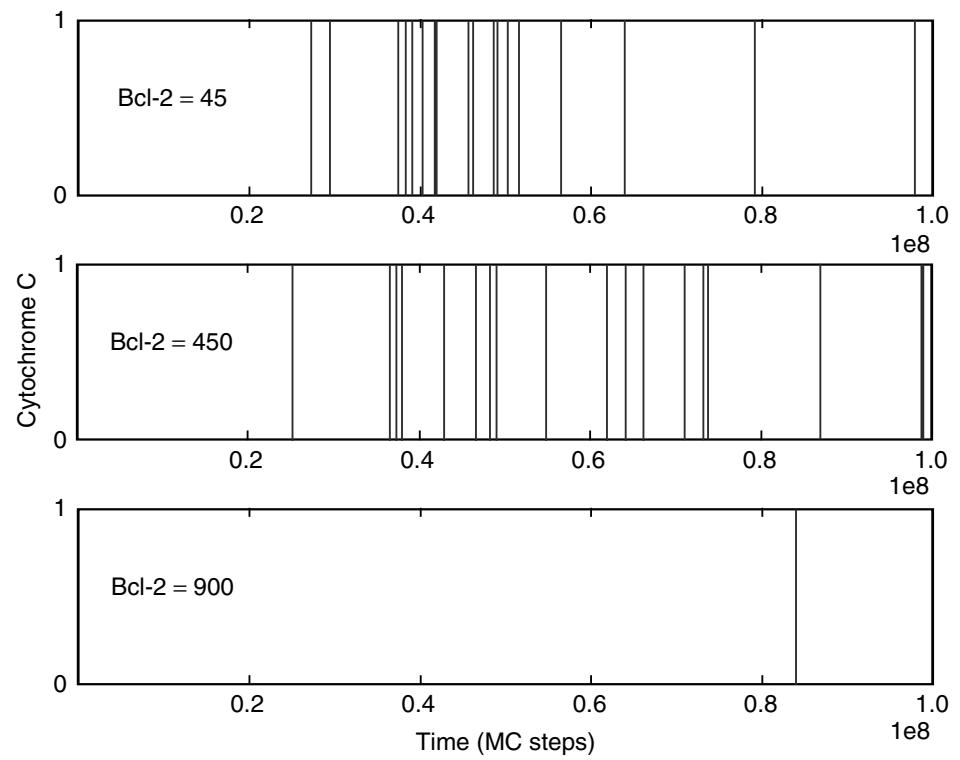

Figure 3. Single cell activations obtained from Monte Carlo (MC) simulations of the intrinsic pathway of apoptosis shown by the release of cytochrome c (rapid all-or-none type release is approximated by a sharp spike) for $\mathrm{Bcl}-2=45,450$, and $900(\mathrm{Bid}=200, \mathrm{Bax}=500)$, respectively. Time is measured in MC steps; data are shown up to $10^{8} \mathrm{MC}$ steps (1 MC step $=10^{-4} \mathrm{sec}$ ). Normalized (relative to maximum cytochrome c) data are shown for single cell runs ( 20 runs for Bcl-2 $=45$ and 18 runs for the rest; each vertical line corresponds to a single cell). For Bcl-2 $=900$ $(\mathrm{Bcl}-2$ to Bax ratio $>1)$, only a small fraction of cells show activation within the given simulation time; it takes up to $3 \times 10^{8} \mathrm{MC}$ steps for all cells to release cytochrome c.

a comparative quantitative study, MESF (molecules of equivalent soluble fluorochrome) of Bcl-2 for CD34+ AML cells was found to vary from 65.1 to $107.6 \times$ $10^{3} /$ cell; MESF of Bcl-2 for the CD34- fraction was much lower, from 33.4 to $82.3 \times$ $10^{3} /$ cell [60]. In a separate quantitative study, similar higher level of Bcl-2 expression was observed in CD34+ AML cells, varying over a wide range of 5.1 to $222 \times 10^{3}$ molecules/cell [61]. In general, CD34+ fraction obtained from the normal bone showed a robust expression of Bcl-2 [60]. In our simulations, keeping the concentrations of Bid and Bax fixed at a 10-fold overexpression while gradually increasing the levels of Bcl-2 diminished Bax activation. The fraction of cells in which cytochrome $\mathrm{c}$ was released, at a given time point, also decreased with increasing concentrations of Bcl-2 (Figure 3). Cell-to-cell stochastic variability in the time-scale of cytochrome c release increased with Bcl-2 levels. Therefore, cellular variability in the amounts of Bid, Bax, and Bcl-2, as may exist among cancer cells of a clonal population, should modulate the susceptibility to apoptotic 
activation and its stochastic variability, and provides a potential mechanism for the generation of CSLCs [37-40]. For very high Bcl-2 concentrations (Bcl-2 to Bax 5), even when Bid and Bax are 10-fold overexpressed, cytochrome c release was significantly inhibited. Such inhibition in cytochrome c release will allow a few cancer cells to acquire additional genetic mutations and generate more malignant, genetically distinct subclones [58-59]. This might also be a relevant mechanism for oncogenesis in cells equipped with higher Bcl-2 expression, such as in CD34+ hematopoietic stem cells.

\subsection{Apoptotic Activation through the Post-Mitochondrial Signaling Module}

Formation of post-mitochondrial apoptosomes, modeled as multimolecular cytochrome c- Apaf complexes, led to additional cell-to-cell variability in caspase 3 activation, as shown in Figure 4. The fraction of apoptotic cells, as measured by caspase 3 activation (1/3 of maximum), is shown in Figure 5 for various values of
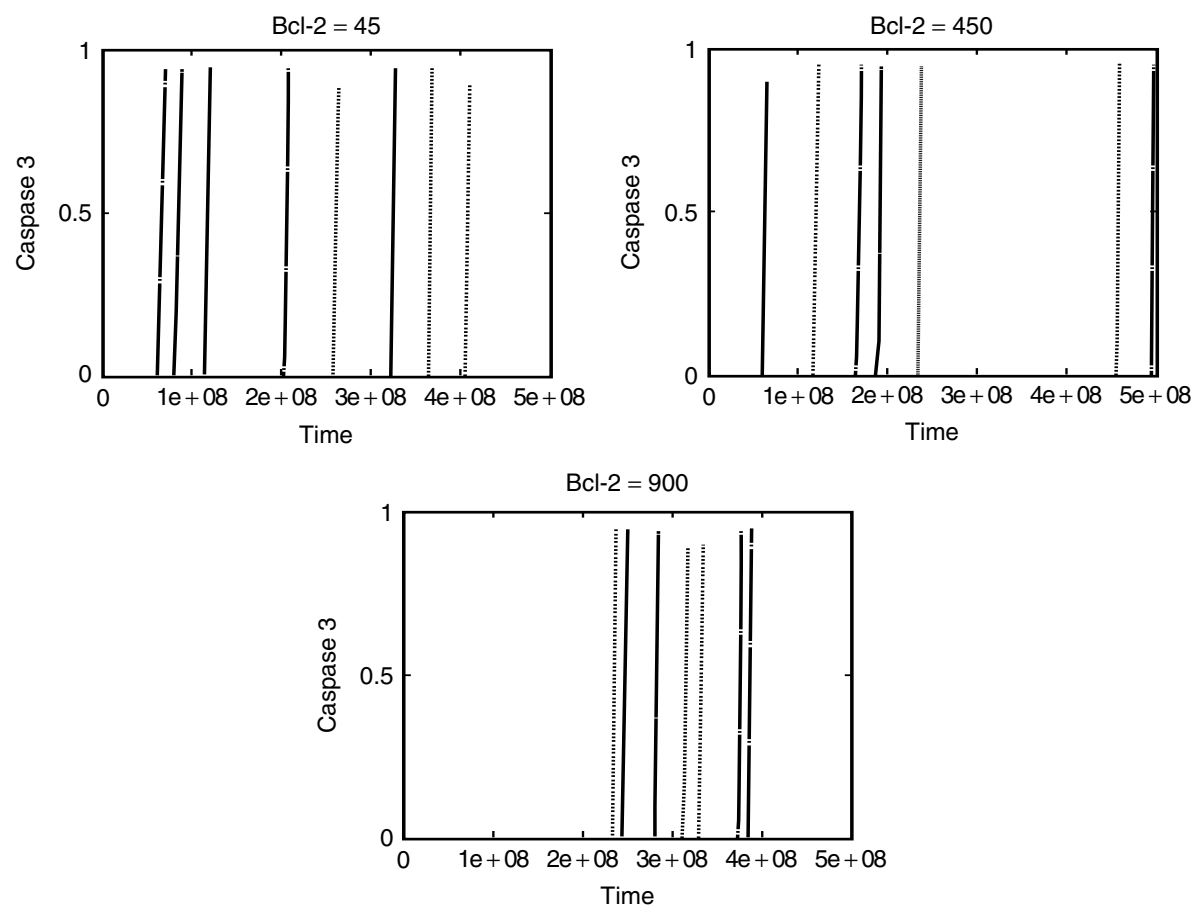

Figure 4. Time course of caspase 3 activation, as readout for downstream apoptotic activation, for single cells. Time is measured in Monte Carlo (MC) steps; simulations are run for $5 \times 10^{8} \mathrm{MC}$ steps $\left(1 \mathrm{MC}\right.$ step $\left.=10^{-4} \mathrm{sec}\right)$. Normalized (relative to $1 / 3$ of full activation) data are shown for Bcl-2 = 45, 450, and $900(\mathrm{Bid}=200, \mathrm{Bax}=500)$, respectively. Data are shown for 10 single cell runs (each vertical line corresponds to a single cell; only a fraction of cells show activation within the given simulation time). 


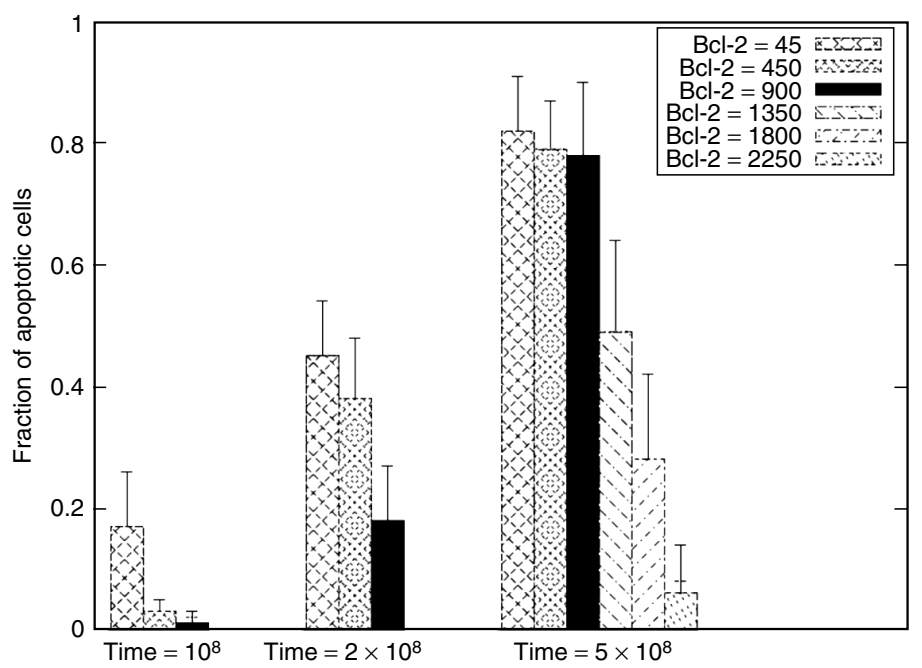

Figure 5. Fraction of apoptotic cells (as measured by $1 / 3$ of full caspase 3 activation) for different values of Bcl-2 inhibition. Data are shown for three different time instants: $t=10^{8}, 2 \times 10^{8}$, and $5 \times 10^{8} \mathrm{MC}$ steps $(1 \mathrm{MC}$ step $\left.=10^{-4} \mathrm{sec}\right)$. Number of runs varies between 6 and 20, decreasing with increasing Bcl-2 values. Cells used to estimate apoptotic activation include cells whose single cell data are shown in Figure 4. Data is not shown if there is no activation.

Bcl-2 inhibition and also at different time instants. The effect of Bcl-2 inhibition on caspase 3 activation is more pronounced at early times ( $10^{8} \mathrm{MC}$ steps $)$ of signaling. In our simulations, Bcl-2 inhibition in the presence of high levels of Bid and Bax significantly diminished cell-to-cell stochastic variability in apoptotic activation of cancer cells, as also found in the theoretical analysis of stochastic equations. Increasing the overexpression level of Bid and Bax while keeping the Bcl-2 to Bax (also Bcl-2 to Bid) ratio fixed, enhanced Bax activation. Hence, the present results suggest that two important cellular parameters modulate cytochrome c release and cell-to-cell variability in apoptosis resistance: (i) over-expression level of Bax and $\mathrm{Bid}$, and (ii) Bcl-2 to Bax ratio. Over-expression of Bax and Bid underlies the specific killing of cancer cells, especially when Bcl-2 inhibition can be removed (e.g., by BH3 mimetics). $\mathrm{Bcl}-2$ to Bax ratio determines the degree of apoptosis resistance and leads to heterogeneity among cancer cells [62-64].

\section{DISCUSSION}

Recent experiments have conclusively shown the existence of large cell-to-cell variability in apoptotic activation through the intrinsic mitochondrial (Type 2) pathway [11-12, 35-36, 56]. All-or-none type behavior in cytochrome c release and capase 9/3 activation, along with cell-to-cell variations in the time-scale of such activation events, characterize large cell-to-cell fluctuations in apoptotic activation. Finding the molecular mechanisms behind the generation of cell-to-cell variability remains a fundamental 
question in the biology of apoptosis. Cellular variability in pro- and anti-apoptotic protein levels that act upstream of mitochondrial outer membrane permeabilization (MOMP), coupled with a rapid release of cytochrome $\mathrm{c}$ once a threshold apoptotic stress has gathered on mitochondria, can cause such cell-to-cell variability in cytochrome c release and thus downstream activation of caspases [11-12, 36]. However, even when all the cellular parameters (such as relevant protein concentrations) remain identical in a cell (including cancer cell) population, inherent stochastic fluctuations in signaling reactions can cause large cell-to-cell stochastic variability [11-12, 33-35, 65-66]. Previous computational studies elucidated the basis for inherent stochastic fluctuations in apoptotic activation of normal and cancer cells [11-12, 33-35]. The present study shows that a low probability Bid-Bax type reaction is another potential mechanism for generating inherent stochastic fluctuations in cell death.

Overexpression of Bid like (BH3 only) proteins and Bax (and/or Bak) proteins, as possibly found in cancer cells, reduces the apoptotic threshold for cancer cells. However, those cells remain protected by highly overexpressed antiapoptotic Bcl-2 like proteins. Hence, cancer cells are inherently different from normal cells [13] and exist in a state of dichotomy. This intrinsic difference between normal and cancer cells allows selective targeting of the cancer cells. Our present study indicates that a low probability Bid-Bax type reaction provides unique opportunities to induce apoptosis in cancer cells (containing higher levels of Bid and Bax proteins). Therefore, such a low-probability reaction event remains highly relevant for apoptosis of cancer cells treated with Bcl-2 inhibitor BH3 (sensitizer) mimetic molecules [1-25]. Such a mechanism, based on low probability activation of Bax (and/or Bak), is also applicable to (i) alternative models of activation such as the one that proposes Bax-Bax interaction (displacement model [25]), and (ii) engineering of BH3 mimetic peptides in cancer therapy [15, 23, 67]. In this context, it will be interesting to analyze the variability among $\mathrm{BH} 3$ activator proteins (in their apoptotic potential) and develop a detailed systems level model that would incorporate all relevant $\mathrm{BH} 3$ only as well as other Bcl-2 family pro- and anti-apoptotic proteins. MC simulations of such a detailed model would allow us to determine the optimal strategy for targeting the pre-mitochondrial signaling module in a cell-type specific manner. Moreover, the concepts of dichotomy and apoptotic vulnerability (in cancer cells) can be extended to various other signaling modules, besides that is formed by the Bcl-2 family proteins, in the Type 2 pathway. It may be of value to explore the possibility of acquired vulnerability that would accompany acquired resistance in cancer cells. Such measurements will be key to activating the Type 2 pathway of cancer cells in a rapid deterministic manner. Alternatively, switching the activation from intrinsic (Type 2) to extrinsic (Type 1) pathway can be a strategy to achieve stochastic-todeterministic transition under certain cellular and physiological conditions [33, 68].

Existence of specialized class of cancer cells, such as CSLCs, is a fundamental issue in cancer biology, that has significant implications for cancer treatment [32, 37-40, 68-69]. Previous experimental studies have indicated that only a small subpopulation 
$(<0.1 \%)$ of melanoma (the most dangerous type of skin cancer) cells possess the ability to form tumors when transplanted into immunodeficient NOD/SCID mice [69]; similar low proportion of tumorigenic cells were reported for different types of cancer [37-40]. Recent in vivo studies, using highly immunocompromised NOD/SCID IL- $2 \mathrm{rg}^{-/-}$mice, however, shows that a large fraction $(\sim 25 \%)$ of such melanoma could form tumors [70]. Thus, two related unanswered questions in cancer biology are (a) how to characterize the subset of cancer cells that can be labeled as CSLCs, and (b) what fraction of cancer cells are actually CSLCs. The heterogeneity in apoptosis resistance of cancer cells (at the level of single cells) may help answer these questions. Stochastic activation due to a low probability of Bid-Bax reaction and cellular variation in protein levels would both make apoptosis resistance (for single cells) heterogeneous. Cell-to-cell variability in protein expressions, which are involved in apoptosis signaling reactions, can occur due to stochastic regulations in relevant gene expressions (even for genetically identical cells) [71-73]. Variability in cellular proteins can also occur due to epigenetic variations and inter-clonal genetic heterogeneity within a tumor population [57-58, 74-77]. In addition, tumor microenvironment (such as CSLC niche) is a major factor in generating and maintaining heterogeneity within a given tumor population [78].

Any types of heterogeneity in apoptosis resistance can be a primary mechanism for generating heterogeneity in tumorigenic potential (within a tumor population). Therefore, single cancer cells will be killed in a stochastic manner in a xenotransplantation assay and only a fraction of cells can survive the assault of activated immune cells. In a modified xenotransplantation assay, such as in severely immunocompromised NOD/SCID IL-2 $\mathrm{rg}^{-/}$mice, less resistant cancer cells having lower Bcl-2 to Bax ratio may survive and produce full-blown tumors. However, only CSLCs that are highly resistant to apoptosis, at least partly due to over-expression of Bcl-2 like proteins (and high Bcl-2 to Bax ratio), would have a higher chance of surviving in NOD/SCID mice. Moreover, inherent stochastic variability and associated fractional cell killing will complicate any quantitative estimation of CSLCs. Further theoretical and experimental studies are needed to elucidate and estimate the fraction of such CSLCs. Even though inherent stochasticity of signaling reactions will still remain a significant factor in apoptosis resistance, the reaction between tBid and Bax (in addition to the Bid-Bax) might be important in the apoptotic death of cancer cells in immunocompromised mice.

Experimental studies, such as those to undertake quantitative measurement of signaling proteins in the apoptotic pathway of cancer cells, including CSLCs, will further clarify the results of our computational studies. Previous experimental studies indicated presence of high Bcl-2 levels in CD34+ fraction of AML cells [59-60]. Leukemic stem cells are found to be CD34+CD38- which presumably also have higher Bcl-2 levels. In earlier studies, CD34+CD38- cell population was found to be only a small fraction in a variety of leukemias including different AML subtypes [32]. This is consistent with the initial observation of low proportion of AML stem cells in NOD/SCID mice [39]. In contrast, in KG1a, a very aggressive form of AML, over $90 \%$ of the cells have the CD34+CD38- phenotype with high $\mathrm{Bcl}-2 / \mathrm{Bax}$ ratio [32]. Therefore, a large percentage of cells may show tumorigenic potential when single 
KG1a cells are transplanted into NOD/SCID mice. In this context, it will be interesting to explore whether variations in tumorigenic potential can result from inherent stochastic fluctuations in apoptosis resistance. In general, a combination of stochastic factors and variations in cellular protein levels would generate significant heterogeneity within a tumor cell population, and such heterogeneity would also heavily depend on the cancer cell type under consideration. Experimental measurement of cellular protein levels will not only elucidate the basis of CSLCs, but is also critical for designing therapeutic strategies to kill CSLCs. In CSLCs, if high antiapoptotic Bcl-2 levels are accompanied with similar high expressions of $\mathrm{BH} 3$ only activators and Bax (keeping the Bcl-2 to Bax ratio fixed), inhibiting Bcl-2 levels may actually lead to more pronounced apoptotic death of CSLCs than that of regular cancer cells. This seems reasonable, as a similar mechanism is also the basis for selective killing of cancer cells. Bcl-2 inhibitor ABT-737 has been shown to induce apoptosis in the CD34+CD38CD123+ leukemia stem cell compartment [79]. However, additional complexities might exist for CSLCs especially for undifferentiated cancer stem cells. For example, the long-term quiescent stem cells may only be targeted when they are driven into a shortterm cycling state [32]. In vitro experiments can be designed to assess apoptotic death of CSLCs by $\mathrm{BH} 3$ mimetic Bcl-2 inhibitors through isolating CSLCs, regular cancer cells and normal cells, and treating each population with $\mathrm{BH} 3$ mimetic Bcl-2 inhibitor to measure apoptosis in the population. If high Bcl-2 expression in CSLCs is accompanied with a high $\mathrm{Bcl}-2$ to Bax ratio, then alternative strategies, such as removing the $\mathrm{Bcl}-2 \mathrm{BH} 4$ domain or opening up the $\mathrm{BH} 3$ domain of $\mathrm{Bcl}-2$ [80] to make it proapoptotic, would selectively kill CSLCs. Bid truncation to tBid, could be another potential option in such cases of high Bcl-2 to Bax ratio.

In addition to its key significance in cancer cell apoptosis (under Bcl-2 inhibitors), direct Bid-Bax type activation might be involved in cell death under a variety of other cellular and physiological situations such as in tissue homeostasis, DNA damaged conditions, or in cancer cells treated with growth inhibitors (or under growth factor withdrawal). Previous experimental studies verified the existence of cell-to-cell variability in the Type 2 activation under the action of a single agent (such as HA14-1) Bcl-2 inhibitor [11-12]. Though cell-to-cell variability (in cytochrome c release) in such studies presumably arises from a Bid-Bax type reaction, the contribution from inherent variability needs to be assessed through quantitative measurement of relevant signaling molecules. Inherent variability through the Bid-Bax reaction can also be revealed by single cell Fluorescence Resonance Energy Transfer (FRET) experiments and analysis of such data in synergy with computational studies.

\section{CONCLUSION}

Using a set of stochastic differential equations and kinetic MC simulations, we studied the stochastic nature of Bax activation that occurs through a low probability Bid-Bax (or a similar) reaction. Apoptosis simulations were conducted for various values of Bid, Bax, and Bcl-2 proteins to gather quantitative information about apoptotic activation. Variations in Bid and Bax levels, as well as the Bcl-2 to Bax ratio, further modulate cellto-cell variability in apoptotic activation resulting from the inherently stochastic Bid- 
Bax reaction. Our results indicate how a stochastic-to-deterministic transition in the pre-mitochondrial signaling module can provide unique opportunity for cancer therapy that relies on the apoptotic activation of the intrinsic pathway.

\section{ACKNOWLEDGEMENT}

We thank Arjun Nair for carrying out data analysis and plotting, and Professor Craig Benham for critical reading of the manuscript.

\section{CONFLICT OF INTEREST}

The authors indicated no potential conflicts of interest.

\section{REFERENCES}

[1] Letai A, Bassik MC, Walensky LD, Sorcinelli MD, Weiler S, Korsmeyer SJ. Distinct BH3 domains either sensitize or activate mitochondrial apoptosis, serving as prototype cancer therapeutics. Cancer Cell, 2002, 2:183-192.

[2] Letai A. BH3 Domains as BCL-2 Inhibitors: Prototypes Cancer Therapeutics. Expert Opinion Biol Ther, 2003, 3:293-304.

[3] Letai A, Sorcinelli MD, Beard C, Korsmeyer SJ. Antiapoptotic BCL-2 is required for maintenance of a model leukemia. Cancer Cell, 2004, 6:241-249.

[4] Chonghaile TN, Letai A. Mimicking the BH3 domain to kill cancer cells. Oncogene, 2008, Suppl 1:S149-157.

[5] Labi V, Grespi F, Baumgartner F, Villunger A. Targeting the Bcl-2-regulated apoptosis pathway by BH3 mimetics: a breakthrough in anticancer therapy? Cell Death Differ, 2008, 15:977-987.

[6] Wang JL, Liu D, Zhang ZJ, Shan S, Han X, Srinivasula SM, Croce CM, Alnemri ES, Huang Z. Structure-based discovery of an organic compound that binds Bcl-2 protein and induces apoptosis of tumor cells. Proc Natl Acad Sci USA, 2000, 97:7124-7129.

[7] Skommer J, Wlodkowic D, Mättö M, Eray M, Pelkonen J. HA14-1, a small molecule Bcl-2 antagonist, induces apoptosis and modulates action of selected anticancer drugs in follicular lymphoma B cells. Leuk. Res, 2006, 30:322-331.

[8] Manero F, Gautier F, Gallenne T, Cauquil N, Grée D, Cartron PF, Geneste O, Grée R, Vallette FM, Juin P. The small organic compound HA14-1 prevents Bcl-2 interaction with Bax to sensitize malignant glioma cells to induction of cell death. Cancer Res, 2006, 66:2757-2764.

[9] Kohl TM, Hellinger C, Ahmed F, Buske C, Hiddemann W, Bohlander SK, Spiekermann K. BH3 mimetic ABT-737 neutralizes resistance to FLT3 inhibitor treatment mediated by FLT3-independent expression of BCL-2 in primary AML blasts. Leukemia, 2007, 21:1763-1772.

[10] High LM, Szymanska B, Wilczynska-Kalak U, Barber N, O’Brien R, Khaw SL, Vikstrom IB, Roberts AW, Lock RB. The Bcl-2 homology domain 3 mimetic ABT-737 targets the apoptotic machinery in acute lymphoblastic leukemia resulting in synergistic in vitro and in vivo interactions with established drugs. Mol. Pharmacol, 2010, 77:483-494.

[11] Skommer J, Brittain T, Raychaudhuri S. Bcl-2 inhibits apoptosis by increasing the time-to-death and intrinsic cell-to-cell variations in the mitochondrial pathway of cell death. Apoptosis, 2010, 15:1223-1233.

[12] Skommer J, Das SC, Nair A, Brittain T, Raychaudhuri S. Nonlinear regulation of commitment to apoptosis by simultaneous inhibition of Bcl-2 and XIAP in leukemia and lymphoma cells. Apoptosis, 2011, 16:619-626.

[13] Certo M, Del Gaizo Moore V, Nishino M, Wei G, Korsmeyer S, Armstrong SA, Letai A. Mitochondria primed by death signals determine cellular addiction to antiapoptotic BCL-2 family members. Cancer Cell, 2006, 9:351-65. 
[14] V. Del Gaizo Moore, A. Letai, BH3 profiling - Measuring integrated function of the mitochondrial apoptotic pathway to predict cell fate decisions. Cancer Lett, 2012, doi:10.1016/j.canlet.2011.12.021.

[15] Walensky LD, Pitter K, Morash J, Oh KJ, Barbuto S, Fisher J, Smith E, Verdine GL, Korsmeyer SJ. A stapled BID BH3 helix directly binds and activates BAX. Mol Cell, 2006, 24:199-210.

[16] Labelle JL, Katz SG, Bird GH, Gavathiotis E, Stewart ML, Lawrence C, Fisher JK, Godes M, Pitter K, Kung AL, Walensky LD. A stapled BIM peptide overcomes apoptotic resistance in hematologic cancers. J Clin Invest, 2012, 122:2018-31.

[17] Bodur C, Basaga H. Bcl-2 inhibitors: emerging drugs in cancer therapy. Curr Med Chem, 2012, 19:1804-20.

[18] Hartman ML, Czyz M. Pro-apoptotic Activity of BH3-only Proteins and BH3 Mimetics: from Theory to Potential Cancer Therapy. Anticancer Agents Med Chem, 2012 (PMID: 22263800).

[19] Khaw SL, Huang DC, Roberts AW. Overcoming blocks in apoptosis with BH3-mimetic therapy in haematological malignancies. Pathology, 2011, 43:525-35.

[20] Fan W, Tang Z, Yin L, Morrison B, Hafez-Khayyata S, Fu P, Huang H, Bagai R, Jiang S, Kresak A, Howell S, Vasanji A, Flask CA, Halmos B, Koon H, Ma PC. MET-independent lung cancer cells evading EGFR kinase inhibitors are therapeutically susceptible to $\mathrm{BH} 3$ mimetic agents. Cancer Res, 2011, 71:4494-505.

[21] Beauchamp EM, Platanias LC. BH3 mimetics and multi-kinase inhibition in AML. Blood, 2012, 119:5947-8.

[22] Rahmani M, Aust MM, Attkisson E, Williams DC Jr, Ferreira-Gonzalez A, Grant S. Inhibition of Bcl-2 antiapoptotic members by obatoclax potently enhances sorafenib-induced apoptosis in human myeloid leukemia cells through a Bim-dependent process. Blood, 2012, 119(25):6089-98.

[23] Gavathiotis E, Reyna DE, Bellairs JA, Leshchiner ES, Walensky LD. Direct and selective smallmolecule activation of proapoptotic BAX. Nat Chem Biol, 2012, doi: 10.1038/nchembio.995.

[24] Nyhan MJ, O’Donovan TR, Elzinga B, Crowley LC, O'Sullivan GC, McKenna SL. The BH3 mimetic HA14-1 enhances 5-fluorouracil-induced autophagy and type II cell death in oesophageal cancer cells. Br J Cancer, 2012, 106:711-8.

[25] Shamas-Din A, Brahmbhatt H, Leber B, Andrews DW. BH3-only proteins: Orchestrators of apoptosis. Biochim Biophys Acta, 2011, 1813:508-20.

[26] Grills C, Fennell DA, Shearer SFC. Markov modelling of mitochondrial BAK activation kinetics during apoptosis, in: Watanabe O, Zeugmann T (eds). SAGA'09 Proceedings of the 5th international conference on Stochastic algorithms: foundations and applications. Springer-Verlag Berlin, Heidelberg, 2009, 191-205.

[27] Hawley RG, Chen Y, Riz I, Zeng C. An Integrated Bioinformatics and Computational Biology Approach Identifies New BH3-Only Protein Candidates. Open Biol J, 2012, 5:6-16.

[28] Ng KP, Hillmer AM, Chuah CT, Juan WC, Ko TK, Teo AS, Ariyaratne PN, Takahashi N, Sawada K, Fei Y, Soh S, Lee WH, Huang JW, Allen JC Jr, Woo XY, Nagarajan N, Kumar V, Thalamuthu A, Poh WT, Ang AL, Mya HT, How GF, Yang LY, Koh LP, Chowbay B, Chang CT, Nadarajan VS, Chng WJ, Than H, Lim LC, Goh YT, Zhang S, Poh D, Tan P, Seet JE, Ang MK, Chau NM, Ng QS, Tan DS, Soda M, Isobe K, Nöthen MM, Wong TY, Shahab A, Ruan X, Cacheux-Rataboul V, Sung WK, Tan EH, Yatabe Y, Mano H, Soo RA, Chin TM, Lim WT, Ruan Y, Ong ST. A common BIM deletion polymorphism mediates intrinsic resistance and inferior responses to tyrosine kinase inhibitors in cancer. Nat Med, 2012, 18:521-8.

[29] Skommer J, Wlodkowic D, Deptala A. Larger than life: Mitochondria and the Bcl-2 family. Leuk. Res, 2007, 31:277-86.

[30] Chipuk JE, Moldoveanu T, Llambi F, Parsons MJ, Green DR. The BCL-2 Family Reunion. Molecular Cell, 2010, 37:299-310.

[31] Petros AM, Olejniczak ET, Fesik SW. Structural biology of the Bcl-2 family of proteins. Biochimica et Biophysica Acta, 2004, 1644:83-94. 
[32] Burger AM. Targeting Leukemic Stem Cells. Cancer Drug Discovery and Development. Stem Cells and Cancer, 2009, 5:263-273.

[33] Raychaudhuri S, Willgohs E, Nguyen TN, Khan EM, Goldkorn T. Monte Carlo simulation of cell death signaling predicts large cell-to-cell stochastic fluctuations through the type 2 pathway of apoptosis. Biophys J, 2008, 95:3559-3562.

[34] Raychaudhuri S. Minimal model of a signaling network elucidates cell-to-cell stochastic variability in apoptosis. PLoS One, 2010, 5:e11930.

[35] Raychaudhuri S, Skommer J, Henty K, Birch N and Brittain T. Neuroglobin protects nerve cells from apoptosis by inhibiting the intrinsic pathway of cell death. Apoptosis, 2010, 15:401-411.

[36] Albeck JG, Burke JM, Spencer SL, Lauffenburger DA, Sorger PK. Modeling a snap-action, variabledelay switch controlling extrinsic cell death. PLoS Biol, 2008, 6:2831-2852.

[37] Reya T, Morrison SJ, Clarke MF, Weissman IL. Stem cells, cancer, and cancer stem cells. Nature, 2001, 414:105-111.

[38] Cox CV, Evely RS, Oakhill A, Pamphilon DH, Goulden NJ, Blair A. Characterization of acute lymphoblastic leukemia progenitor cells. Blood, 2004, 104:2919-2925.

[39] Dick JE. Acute myeloid leukemia stem cells. Ann N Y Acad Sci. 2005, 1044:1-5.

[40] Clevers H. The cancer stem cell: premises, promises and challenges. Nature Med, 2011, 17:313-319.

[41] Watters D, Lavin M. (ed) Signaling Pathways in Apoptosis. Hardwood academic publishers, 1999.

[42] Billen LP, Shamas-Din A and Andrews DW. Bid: a Bax-like BH3 protein. Oncogene, 27, 2009, S93-S104.

[43] Cabon L, Galán-Malo P, Bouharrour A, Delavallée L, Brunelle-Navas MN, Lorenzo HK, Gross A, Susin SA. BID regulates AIF-mediated caspase-independent necroptosis by promoting BAX activation. Cell death and Differ, 2012, 19:245-256.

[44] Korsmeyer SJ, Wei MC, Saito M, Weiler S, Oh KJ, Schlesinger PH. Pro-apoptotic cascade activates $\mathrm{BID}$, which oligomerizes BAK or BAX into pores that result in the release of cytochrome c. Cell Death and Differ, 2000, 7:1166-1173.

[45] McDonnell JM, Fushman D, Milliman CL, Korsmeyer SJ, Cowburn D. Solution Structure of the Proapoptotic Molecule BID: A Structural Basis for Apoptotic Agonists and Antagonists. Cell, 1999, 96:625-634.

[46] Hua F, Cornejo MG, Cardone MH, Stokes CL, Lauffenburger DA. Effects of Bcl-2 Levels on Fas signaling induced caspase 3 activation: molecular genetic tests of computational model predictions. $J$ Immunol, 2005, 175:985-995.

[47] Goldstein JC, Waterhouse NJ, Juin P, Evan GI, Green DR. The coordinate release of cytochrome c during apoptosis is rapid, complete and kinetically invariant. Nat Cell Biol, 2000, 2:156-162.

[48] Gardiner CW. Handbook of stochastic methods for Physics, Chemistry and the natural Sciences. Springer-Verlag, 1990.

[49] Manninen T, Linne ML, Ruohonen K. Developing Itô stochastic differential equation models for neuronal signal transduction pathways. Comput Biol Chem, 2006, 30:280-291.

[50] Burrage K, Tian T. in Advances in Scientific Computing and Applications, eds Lu, Y.Y., Sun, W., Tang, T. Science Press, 2004, pp. 82-96.

[51] Kloeden PE, Platen E, Schurz H. Numerical Solution of SDE through computer experiments. Springer, 1994.

[52] Eising TH, Conzelman ED, Allgower F, Bullinger E, and Scheurich P. Bistability analyses of a caspase activation model for receptor-induced apoptosis. J Biol Chem, 2004, 279:36892-36897.

[53] Bagci EZ, Vodovotz Y, Billiar TR, Ermentrout GB, Bahar I. Bistability in apoptosis: Roles of Bax, Bcl-2 and mitochondrial permeability transition pores. Biophys $J$, 2006, 90:1546-1559.

[54] Sun XM, Bratton SB, Butterworth M, MacFarlane M, Cohen GM. Bcl-2 and Bcl-xL inhibit CD95mediated apoptosis by preventing mitochondrial release of Smac/DIABLO and subsequent inactivation of x-linked Inhibitor-of-apoptosis protein. J Biol Chem, 2002, 277:11345-11351. 
[55] Legewie S, Blüthgen N, Herzel H. Mathematical Modeling Identifies Inhibitors of Apoptosis as Mediators of Positive Feedback and Bistability. PLoS Comp Biol. 2006, 2:1061-1073.

[56] Lee JK, Lu S, Madhukar A. Real-Time dynamics of Ca2+, Caspase 3/7, and morphological changes in retinal ganglion cell apoptosis under elevated pressure. PLoS One, 2010, 5:e13437.

[57] Li H, Zhu H, Xu CJ, Yuan J. Cleavage of BID by caspase 8 mediates the mitochondrial damage in the Fas pathway of apoptosis. Cell, 1998, 94:491-501.

[58] Anderson K, Lutz C, van Delft FW, Bateman CM, Guo Y, Colman SM, Kempski H, Moorman AV, Titley I, Swansbury J, Kearney L, Enver T, Greaves M. Genetic variegation of clonal architecture and propagating cells in leukaemia. Nature, 2011, 469:356-361.

[59] Notta F, Mullighan CG, Wang JC, Poeppl A, Doulatov S, Phillips LA, Ma J, Minden MD, Downing JR, Dick JE. Evolution of human BCR-ABL1 lymphoblastic leukaemia-initiating cells. Nature, 2011, 469:362-367.

[60] Bradbury DA, Russel NH. Comparative quantitative expression of bcl-2 by normal and leukaemic myeloid cells. B J Haemot, 1995, 9:374-379.

[61] Porwit-MacDonald A, Ivory K, Wilkinson S, Wheatley K, Wong L, Janossy G. Bcl-2 protein expression in normal human bone marrow precursors and in acute myelogenous leukemia. Leukemia, 1995, 9:1191-1198.

[62] Aguilar-Santelises M, Rottenberg ME, Lewin N, Mellstedt H, Jondal M. Bcl-2, Bax and p53 expression in B-CLL in relation to in vitro survival and clinical progression. Int J Cancer, 1996, 69:114-119.

[63] Kitada S, Andersen J, Akar S, Zapata JM, Takayama S, Krajewski S, Wang HG, Zhang X, Bullrich F, Croce CM, Rai K, Hines J, Reed JC. Expression of apoptosis-regulating proteins in chronic lymphocytic leukemia: correlations with In vitro and In vivo chemoresponses. Blood, 1998, 91:3379-3389.

[64] Menendez P, Vargas A, Bueno C, Barrena S, Almeida J, De Santiago M, López A, Roa S, San Miguel JF, Orfao A. Quantitative analysis of bcl-2 expression in normal and leukemic human B-cell differentiation. Leukemia, 2004, 18:491-498.

[65] Skommer J, Raychaudhuri S, Wlodkowic D. Timing is everything: stochastic origins of cell-to-cell variability in cancer cell death. Front Biosci, 2011, 16:307-314.

[66] Raychaudhuri S. How can we kill cancer cells: Insights from the computational models of apoptosis. World J Clin Oncol, 2010, 1:24-28.

[67] Oh KJ, Barbuto S, Pitter K, Morash J, Walensky LD, Korsmeyer SJ. A membrane-targeted BID BCL2 homology 3 peptide Is sufficient for high potency activation of BAX in vitro. $J$ Biol Chem, 2006, 281:36999-37008.

[68] Kurita S, Mott JL, Cazanave SC, Fingas CD, Guicciardi ME, Bronk SF, Roberts LR, FernandezZapico ME, Gores GJ. Hedgehog Inhibition Promotes a Switch from Type II to Type I Cell Death Receptor Signaling in Cancer Cells. PLoS One, 2011, 6:e18330.

[69] Schatton T, Murphy GF, Frank NY, Yamaura K, Waaga-Gasser AM, Gasser M, Zhan Q, Jordan S, Duncan LM, Weishaupt C, Fuhlbrigge RC, Kupper TS, Sayegh MH, Frank MH. Identification of cells initiating human melanomas. Nature, 2008, 451:345-349.

[70] Quintana E, Shackleton M, Sabel MS, Fullen DR, Johnson TM, Morrison SJ. Efficient tumour formation by single human melanoma cells. Nature, 2008, 456:593-598.

[71] McAdams HH, Arkin A. It's a noisy business! Genetic regulation at the nanomolar scale. Trends Genet, 1999, 15:65-69.

[72] Elowitz MB, Levine AJ, Siggia ED, Swain PS. Stochastic gene expression in a single cell. Science, 2002, 297:1183-1186. 
[73] Sigal A, Milo R, Cohen A, Geva-Zatorsky N, Klein Y, Liron Y, Rosenfeld N, Danon T, Perzov N, Alon U. Variability and memory of protein levels in human cells. Nature, 2006, 444: 643-646.

[74] Shackleton M, Quintana E, Fearon ER, Morrison SJ. Heterogeneity in cancer: cancer stem cells versus clonal evolution. Cell, 2009, 138:822-829.

[75] Greaves M. Cancer stem cells: Back to Darwin? Seminars in Cancer Biol, 2010, 20:65-70.

[76] Girouard SD, Murphy GF. Melanoma stem cells: not rare, but well done. Lab Invest, 2011, 91:647-664.

[77] Vyas P, Jacobsen SE. Clever Leukemic Stem Cells Branch Out. Cell Stem Cell, 2011, 8:242-244.

[78] Borovski T, De Sousa E Melo F, Vermeulen L, and Medema JP. Cancer Stem Cell Niche: The Place to Be. Cancer Res, 2011, 71; 634-639.

[79] Samudio I, Konopleva M, Carter B, Andreeff M. Apoptosis in leukemias: regulation and therapeutic targeting. Cancer Treat Res, 2010, 145:197-217.

[80] Thompson J, Winoto A. During negative selection, Nur77 family proteins translocate to mitochondria where they associate with Bcl-2 and expose its proapoptotic BH3 domain. J Exp Med, 2008, 205:1029-1036.

\section{APPENDIX: SIMULATION PARAMETERS}

Kinetic reaction rates and molecular concentrations are obtained from values reported in the literature [46, 52-55] or used in our previous studies [11-12, 33, 35]. Table A1 presents the initial molecular numbers. Molecular number for a given simulation volume is estimated by $\sim 0.6 \times$ nano-molar concentration $\left(1 / \mu \mathrm{m}^{3}\right) \times V\left(\mu \mathrm{m}^{3}\right)$. Probabilistic rate constants used in this study are obtained from kinetic rate constants using a previously described parameter mapping scheme [33]. $P_{\text {off }}\left(\right.$ or $P_{\text {cat }}$ ) simulation parameters are obtained by multiplying $k_{\text {on }}$ (or $k_{\text {cat }}$ ) values by $10^{-4} \mathrm{sec}$ ( $1 \mathrm{MC}$ time-step). Probabilistic parameters for association reactions are determined using the following relation: $P_{o n}=10^{2} \times k_{o n} \mathrm{nM}^{-1} \mathrm{~s}^{-1}$ [33]. Values for probabilistic simulation parameters are provided in Table A2. An approximate estimate for the Bid-Bax and Bid-Bcl-2 reaction constants are discussed in section 2.4.

Table A1. Initial number of molecules

\begin{tabular}{lr}
\hline Molecule type & Number of molecul \\
\hline Bid & 20 \\
Bax & 50 \\
Bcl-2 & 60 \\
Cytochrome C & 60 \\
Smac & 60 \\
Apaf & 20 \\
XIAP & 18 \\
ProCaspase 9 & 12 \\
ProCaspase 3 & 60
\end{tabular}


Table A2. Probabilistic reaction parameters

Probabilistic parameters used in the Monte Carlo simulation

$\left(\boldsymbol{P}_{\text {on }} / \boldsymbol{P}_{\text {off }} / \boldsymbol{P}_{\text {cat }}\right)$

Value

$P_{\text {on_Bid-Bax }}$

$10^{-4}$

$P_{\text {off_Bid-Bax }}$

$10^{-6}$

$P_{\text {on_ }}$ Bid-Bcl-2

$10^{-3}$

$P_{\text {off_Bid-Bcl-2 }}$

$10^{-6}$

$P_{\text {on_Bax-Bcl-2 }}$

$2 \times 10^{-1}$

$P_{\text {off_Bax-Bcl-2 }}$

$2 \times 10^{-6}$

$P_{\text {on_CytoC-Apaf }}$

$2.8 \times 10^{-5}$

$P_{\text {off_CytoC-Apaf }}$

$5.7 \times 10^{-7}$

$P_{\text {on_Apaf-Apaf }}$

1.0

$P_{\text {off_Apaf-Apaf }}$

$10^{-3}$

$P_{\text {on_Apoptosome-ProCaspase } 9}$

$2.8 \times 10^{-2}$

$P_{\text {off_Apoptosome-ProCaspase } 9}$

$7.5 \times 10^{-6}$

$P_{\text {cat_C CytoC-ProCaspase } 9}$

$7 \times 10^{-5}$

$P_{\text {on_ XIAP-Smac }}$

$7 \times 10^{-1}$

$P_{\text {off_-XIAP-Smac }}$

$2.2 \times 10^{-7}$

$P_{\text {on_XIAP-ProCaspase } 9}$

$5 \times 10^{-1}$

$P_{\text {off_-XIAP-ProCaspase } 9}$

$3.5 \times 10^{-7}$

$P_{\text {on_ XIAP-Caspase } 9}$

$5 \times 10^{-1}$

$P_{\text {off_XIAP-Caspase } 9}$

$3.5 \times 10^{-7}$

$P_{\text {on_XIAP-Caspase } 3}$

$2.5 \times 10^{-1}$

$P_{\text {off_XIAP-Caspase } 3}$

$2.5 \times 10^{-7}$

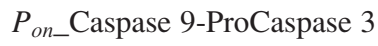

$2 \times 10^{-3}$

$P_{\text {off_Caspase }}$ 9-ProCaspase 3

$5.7 \times 10^{-5}$

$P_{\text {cat_Caspase 9-ProCaspase } 3}$

$4.8 \times 10^{-4}$

$P_{\text {on_Caspase 3-ProCaspase } 9}$

$8 \times 10^{-3}$

$P_{\text {on_Caspase 3-ProCaspase } 9}$

$5.7 \times 10^{-5}$

$P_{\text {cat_Caspase 3-ProCaspase } 9}$

$4.8 \times 10^{-4}$ 


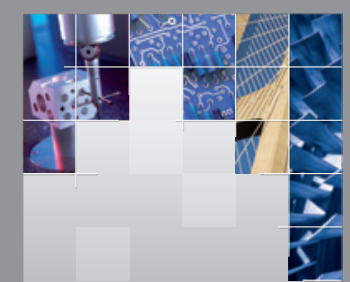

\section{Enfincering}
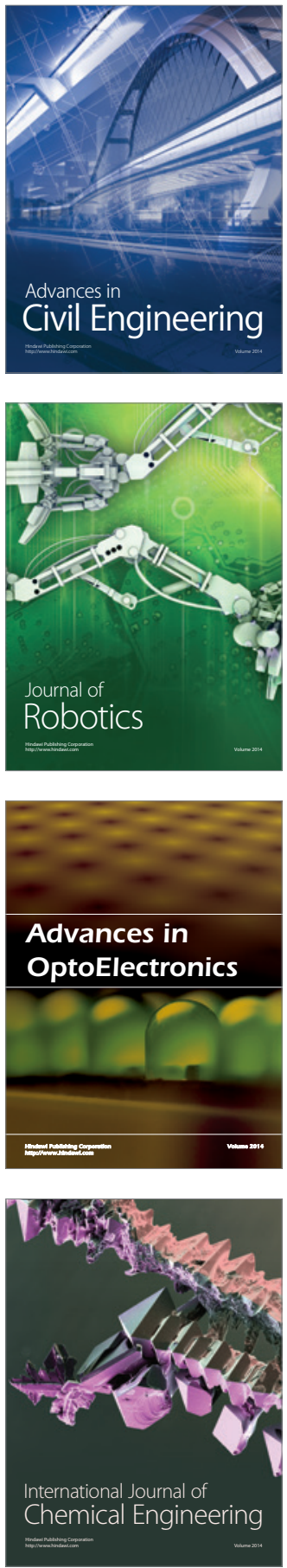

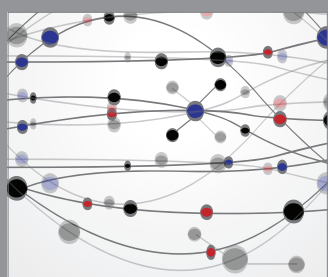

The Scientific World Journal

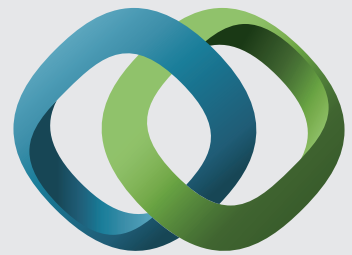

\section{Hindawi}

Submit your manuscripts at

http://www.hindawi.com
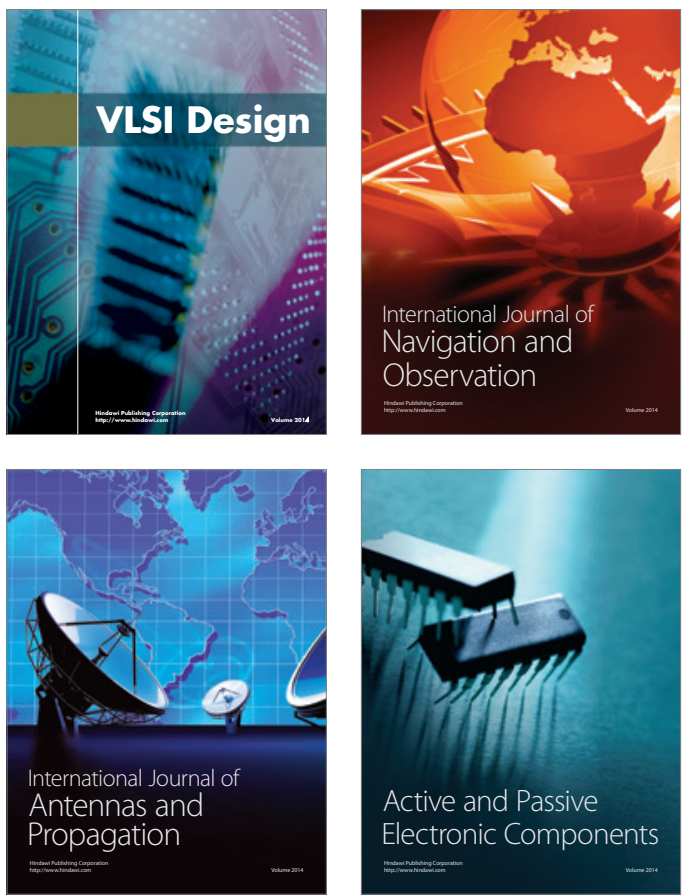
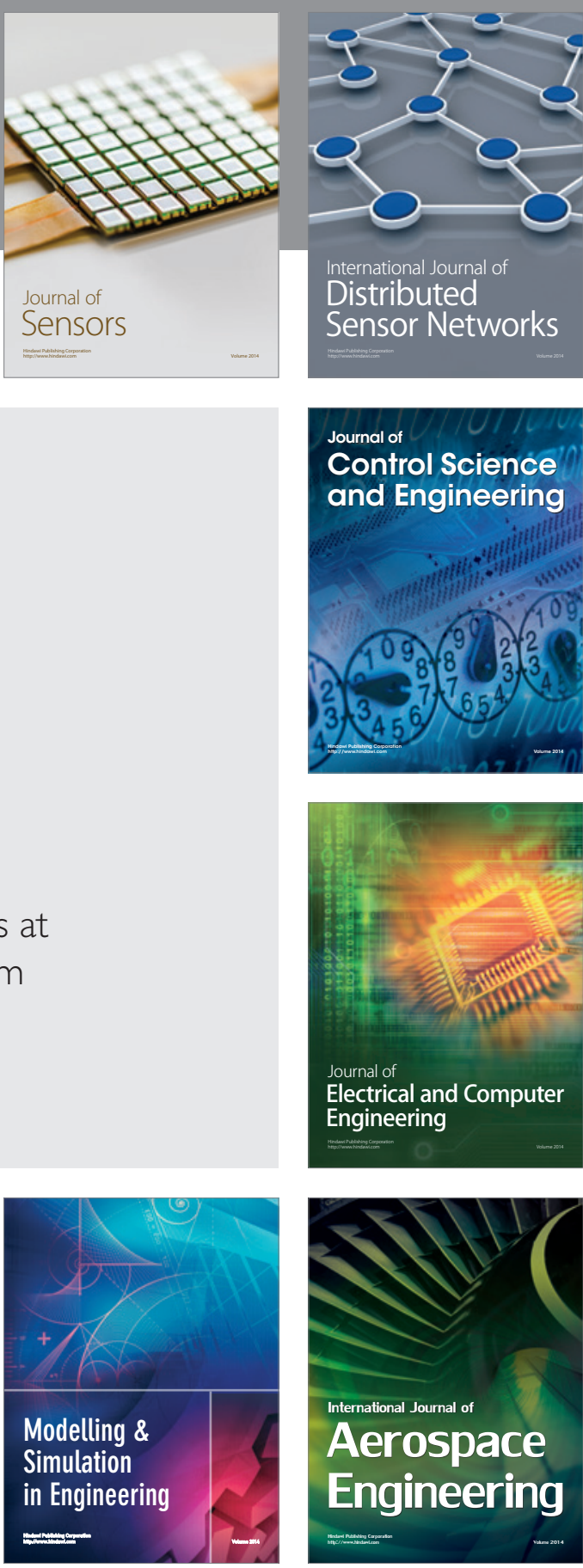

International Journal of

Distributed

Sensor Networks

Journal of

Control Science

and Engineering
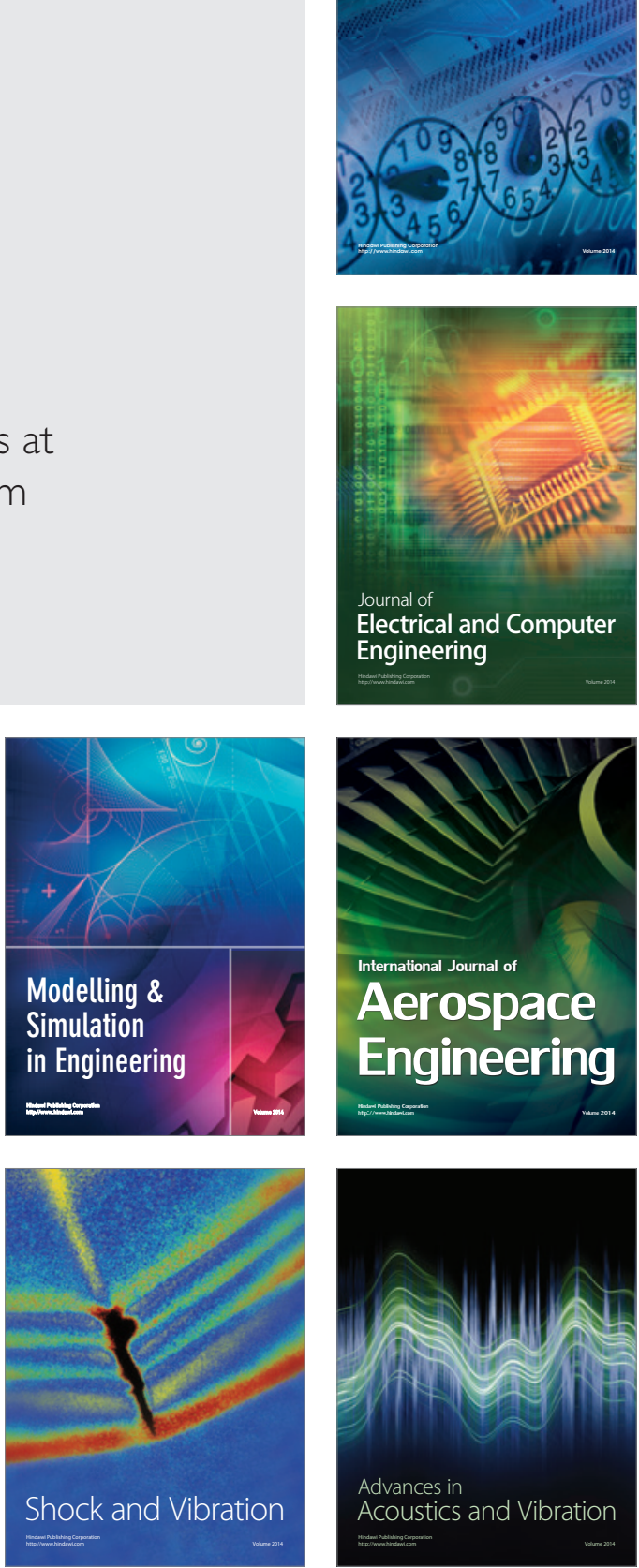